AC 2009-1423: SUMMER NUCLEAR ENGINEERING INSTITUTE FOR TEXAS AND BIG-12 UNDERGRADUATES

Erich Schneider, University of Texas, Austin

Steven Biegalski, University of Texas, Austin

David Hearnsberger, University of Texas, Austin

Sheldon Landsberger, University of Texas, Austin 


\title{
Summer Nuclear Engineering Institute for Texas and Big- 12 Undergraduates
}

\begin{abstract}
Through a US Nuclear Regulatory Commission grant we have established a Summer Nuclear Engineering Institute for Texas and Big-12 undergraduate students to ameliorate their educational experience at their home institution. The Institute, which will be held for the first time in the summer of 2009, will serve undergraduates from outside of The University of Texas at Austin (UT-Austin) who are pursuing a degree in a discipline other than nuclear engineering (NE) as well as those who are working toward NE degrees at schools without a research reactor.
\end{abstract}

\section{Introduction}

Growth in the supply of trained engineers for the nuclear industry has been exceeded by demand growth. Nuclear engineers have been in high demand because of the high turnover in the aging industrial workforce; however the construction of a generation of new nuclear power plants will play an even more significant role in the employment dynamics of the industry. Domestic utilities have announced plans to construct nearly thirty new plants over the next decade and a half. Operational and support staffing requirements for these new plants will be considerable: it has been estimated that a demand for tens of thousands of engineers working in nuclear-related disciplines will develop ${ }^{1}$. Of more pressing concern is the design, engineering, licensing and regulatory work needed to bring these plans to fruition. Demand for skilled employees in these areas is affecting a profound and immediate impact on the nuclear job market.

Three examples serve to illustrate the pressing need for young talent at the outset of the pathway to the nuclear renaissance. Westinghouse Electric, a major reactor vendor and provider of operational support services, has publicized its need for 500 trained engineers per year for the foreseeable future in a number of venues including a seminar given at UT-Austin in the fall of 2007. The US Nuclear Regulatory Commission (NRC) faces a demand for new talent on a similar scale and has been hiring between 300 and 400 employees per year in recent years ${ }^{2}$. Finally, AREVA, the largest nuclear fuel cycle service provider in the world, added over 4,000 employees in $2007 \mathrm{alone}^{3}$, a considerable portion of which were affiliated with AREVA's North American operations.

The primary objective of the Institute is to therefore to impart upon future nuclear professionals, including those from non-nuclear academic disciplines, the practical skills they will need when working in proximity to a nuclear reactor or in an environment where radiological hazards are present. We have structured the Institute around two intensive two-week academic sessions with a classroom environment in the morning and laboratory experiments in the afternoon. The 1 Megawatt TRIGA reactor at UT-Austin will therefore play a central role in the Institute curriculum, as will the health physics instrumentation maintained at UT-Austin. The strong practical and experimental component of the Institute curriculum will be complemented by the classroom lectures. 
These provide a sound grounding in the fundamentals of health physics, nuclear reactor physics and nuclear systems engineering.

\section{Institute Overview and Curriculum}

We have enrolled sixteen students in the Institute, which is taking place in July 2009. The students are drawn from Texas institutions not offering undergraduate NE programs as well as Big 12 schools lacking research reactors. Admission to the Institute has taken place on a competitive basis; to foster further diversity among our student body, we reached outside the schools we had targeted for recruitment to accept applicants from Florida Memorial and North Carolina A\&T State Universities. Applications were accepted from students holding sophomore or junior standing at their home institution. The applications included a transcript, resume, one letter of reference and most importantly a statement of personal interest in the objectives of the Institute.

We took several measures to promote the Institute. First, publicity materials including brochures and a webpage (http://snei.engr.utexas.edu) were developed. We undertook two recruitment trips in Fall 2008, one to Texas Southern and another to The University of Texas of the Permian Basin. The recruitment presentations were made in the context of a guest lecture at a survey course. The presentations and recruitment materials focused not only on the Institute curriculum but also on the careers for which the Institute is geared to help prepare its graduates.

Institute graduates are paid a stipend of $\$ 1000$ and textbook allowance of $\$ 200$. Finally, the students will be reimbursed for travel expenses of up to $\$ 500$ and receive six UTAustin course credits that may be freely transferred to their home institution. Moreover, the graduates will have gained rare and valuable hands-on experience that will serve to enhance their employment value within the nuclear industry - and, we anticipate, sharpen their desire to pursue nuclear careers.

In this section we first discuss the curriculum proposed for the two intensive short courses that comprise the Institute, Health Physics and Nuclear Reactor Engineering. We then turn to the logistical and mechanical tasks that will be performed to bring the Institute to fruition and ensure positive student experiences. Note that all lectures will be recorded in our video classroom and lecture materials will be available to the students as PowerPoint presentations.

\section{Curriculum: Health Physics}

The first two week module, Health Physics: Theoretical Aspects and Applications and Health Physics Instrumentation, will be taught with the supposition that the undergraduate students have little background in this area.

The two week course in health physics will be divided up into two distinct fractions. The morning session will incorporate 3 fifty minute lectures on the basics of health physics. 
There will be a total of four lecture days each week with a grand total of 24 lectures. At the end of each week there will be a short exam.

\section{Health Physics Instrumentation}

The Health Physics Instrumentation Module will offer half-day lectures, followed by practical hands-on experience with a variety of portable and laboratory radiation instruments. Half of each day will be devoted to practical hands-on exercises, which will cover instrument calibration collection of survey and dosimetry measurements.

The course will cover the following:

- Radiation Counting Statistics; Discuss briefly the calculation of

○ Standard deviation of counts,

- Confidence Limits,

- $\chi^{2}$ Criterion for data rejection,

- Chauvenet's Criterion for data rejection,

○ Optimizing source count time for a given background,

- Instrument efficiency,

Lower Limits of Detection (LLD), and

- Minimum Detectable Activity (MDA),

- Detector dead time and its correction.

\section{- Review of}

○ Nuclear and Atomic Physics,

- Photon, Neutron, and Charged Particle Interactions,

- Decay Kinetics, and

- Source to Receptor Geometries

\section{- Gas Filled Detectors}

- Introduction to Gas Amplification,

- Operation of Ionization Chambers, with discussion of energy independence, and daily source response checks.

- Operation of Gas Flow Proportional Counters;

- Discuss Quench gases,

- Discuss Pulse shaping,

- Discuss and observe changes in count rate with changes in voltages,

- Perform plateau determinations for beta and alpha radiations

- Observe energy independence by establishing plateaus with two different beta energy-emitting radionuclides.

○ Operation of a Geiger-Müller (G-M) Counter, including

- Discuss Quenching,

- Discuss Pulse shaping,

- Dead time and its correction using the source technique,

- Observe energy dependence from two different gamma-emitting radionuclides. 


\section{- Solid and Plastic Scintillators}

- Discuss the Scintillation Process for Inorganic Scintillators,

- Discuss the properties of Inorganic Scintillators,

- Discuss the Scintillation Process for Plastic Scintillators,

○ Discuss the relationship between pulse height and energy and type of incident radiation,

- Discuss the detector responses to different types of radiation and the signal processing (i.e. explanation of light pulses, photocathodes, PMTs, amplifiers, pulse heights, and counts),

○ Measure the resolution of the detection system for gamma-rays of different energy;

o Determine the energy of the photopeaks from an unknown gamma emitter and identify the isotope; and

- Observe the effect of scattering materials on spectra;

\section{- High Purity Germanium Detectors}

- Discuss properties of Semi-Conductors

- Comparison of resolution to inorganic scintillators,

- Comparison of efficiency to inorganic scintillators,

- Identify naturally occurring radioactive materials,

- Identify fission products identification using gamma ray spectrometry;

- Determine the energy of the photopeaks from an unknown gamma emitter and identify the radionuclide; and

- Observe the effect of scattering materials on spectra;

\section{- Personnel Monitoring with Radiation Survey Instruments;}

$\circ$ Learn personnel frisking techniques for alpha and beta radiation emitting radionuclides with different instrument types such as GM detectors and plastic scintillators.

- Observe different response times from several different types of instruments.

$\circ$ Learn donning and doffing when entering/exiting to/from an area that requires and Radiation Work Permit (RWP).

- Learn to count air samples on several types of instrument such as GM detectors, plastic scintillators, and gas flow proportional counters.

- Calculate the DAC and ALI based on a particular air sample result.

- Neutron Shielding,

- Learn how to obtain neutron dose rate readings,

- Observe changes in dose rates with several different types of shielding materials.

\section{- Gamma-Ray Shielding}

○ Discuss the inverse square law,

$\circ$ Discuss the half-value layer and the tenth value layer. 
○ Observe how shielding with different materials gamma ray exposure rates.

\section{- Reactor Health Physics}

○ Conduct routine radiation and contamination surveys while the $1.1 \mathrm{MW}$

Triga reactor is operational.

- Conduct the same surveys when the reactor is not operational.

$\circ$ Discuss the reasons why some areas exhibit similar readings while others are different.

- Discuss how this affects personnel monitoring controls.

$\circ$ Demonstrate how to enter/exit areas that require RWPs while conducting these surveys.

The course will emphasize how to choose the best instruments for the student's needs, depending on a few different occupations. Additional instruction will be given on how to set up and assure that instruments are working properly, how to properly use each instrument, and how to check each instrument for proper response. The course also provides instruction on how to interpret radiation measurements, quality assurance, and how to troubleshoot instruments.

Participants will receive an extensive Radiation Instruments Manual, a certificate of training, and a final written and practical hands-on exam.

$\underline{\text { Health Physics Laboratory }}$

The Nuclear Engineering Teaching Lab has all new state-of-the-art HP equipment. It is anticipated that there will be approximately 16 students broken up into groups of 3 per station. If needed the laboratory time can be extended into the evening. At the end of each week there will be a short exam. Each student will be required to write 3 complete lab reports and only do the data analysis for the other labs.

The afternoon session, held each day between 1 and 4:30 PM, will consist of a lecture related to the laboratory. The eight instrumentation experiments will include:

1. Operation of a Geiger-Müller $(G-M)$ Counter will be investigated, including the twosource method of dead-time determination;

2. Determination of Environmental And Fission Product Gamma-Ray Radiation Using a Hyperpure Germanium Counter; to identify naturally occurring radioactive materials as well as fission product identification using gamma ray spectrometry

3. Radiation Counting Statistics; objective of this experiment is to become familiar with the operation of a windowless flow proportional counter for measuring alpha and beta radiation. The application of statistics to data obtained from counting radiation will also be investigated;

4. Personnel Monitoring Devices and Radiation Survey Instruments; to become familiarized with personnel monitoring devices and radiation survey instruments and to determine the response of the various survey instruments to different types of radiation 
5. Gamma-Ray Spectrometry With A Sodium Iodide Detector; to measure the resolution of the detection system for gamma-rays of different energy; to determine the energy of the photopeaks from an unknown gamma emitter and identify the isotope; and to observe the effect of scattering materials on spectra

6. Neutron Shielding, objective is to shield a neutron source to shield various materials

7. Gamma-Ray Shielding, objective would be to shield a Cs-137 with various materials

8. Reactor Health Physics, to make gamma and neutron measurements around the reactor and in the beam ports when it is operated running a full power.

\section{Curriculum: Nuclear Reactor Engineering}

The second two week module, Nuclear Reactor Engineering, will also be taught under the assumption that the students have no special background knowledge of reactors.

Therefore, the students will be exposed to the basic physical and engineering concepts of nuclear reactor design and operation with only the appropriate university-level mathematics background assumed.

The morning session will incorporate two one hour and fifteen minute lectures separated by a fifteen minute break. The early morning series of lectures will present elementary reactor physics, while the late morning lectures will address engineering aspects of reactor operation. The early morning lectures in particular will be topically tied to the afternoon laboratories, which take place daily as well.

\begin{tabular}{|c|c|c|c|}
\hline \multicolumn{4}{|c|}{ Nuclear Engineering Summer Course Schedule (2 Weeks) } \\
\hline & \multicolumn{2}{|c|}{ Morning } & \multirow{2}{*}{\begin{tabular}{|l|} 
Afternoon \\
Laboratory
\end{tabular}} \\
\hline Week 1 & Reactor Physics & \begin{tabular}{|l|} 
Reactor \\
Engineering
\end{tabular} & \\
\hline Monday & $\begin{array}{l}\text { Introduction - } \\
\text { Fundamental } \\
\text { Particles }\end{array}$ & Heat Removal & Reactor Tour with Startup \\
\hline Tuesday & $\begin{array}{l}\text { Interactions and } \\
\text { Radioactive Decay }\end{array}$ & $\begin{array}{l}\text { Two Phase Flow } \\
\text { and Departure } \\
\text { from Nucleate } \\
\text { Boiling } \\
\end{array}$ & Half-Life Measurement \\
\hline Wednesday & $\begin{array}{l}\text { Cross Sections; } \\
\text { Fission }\end{array}$ & $\begin{array}{l}\text { Thermodynamic } \\
\text { Cycles }\end{array}$ & Neutron Activation Analysis \\
\hline Thursday & $\begin{array}{l}\text { Physics of } \\
\text { Multiplying } \\
\text { Systems }\end{array}$ & Fuel Depletion & Subcritical Multiplication \\
\hline Friday & $\begin{array}{l}\text { Critical Reactors; } \\
\text { Six-factor Formula }\end{array}$ & $\begin{array}{l}\text { Economics and } \\
\text { Design Principles }\end{array}$ & Prompt Jump and Prompt Drop \\
\hline \multicolumn{4}{|l|}{ Week 2} \\
\hline Monday & Reactivity, Reactor & Light Water & Xenon Buildup \\
\hline
\end{tabular}




\begin{tabular}{|l|l|l|l|}
\hline & Control & Reactors & \\
\hline Tuesday & $\begin{array}{l}\text { Time Dependence } \\
\text { of Chain Reacting } \\
\text { Systems }\end{array}$ & $\begin{array}{l}\text { Other } \\
\text { Commercial } \\
\text { Reactor Designs }\end{array}$ & $\begin{array}{l}\text { Fuel Temperature Coefficient of } \\
\text { Reactivity }\end{array}$ \\
\hline Wednesday & $\begin{array}{l}\text { The Diffusion } \\
\text { Model of Neutron } \\
\text { Spatial Distribution }\end{array}$ & $\begin{array}{l}\text { Next Generation } \\
\text { Reactors }\end{array}$ & Power Calibration \\
\hline Thursday & $\begin{array}{l}\text { Numerical Model } \\
\text { of a Reactor }\end{array}$ & $\begin{array}{l}\text { Nuclear } \\
\text { Regulation and } \\
\text { Licensing }\end{array}$ & Reactor Pulse \\
\hline Friday & Exam & Exam & Final Summary \\
\hline
\end{tabular}

\section{$\underline{\text { Reactor Physics }}$}

The first lecture session each morning will be devoted to the physics of nuclear interactions, chain reactions and nuclear reactors. Assuming little foreknowledge of the relevant physics, the lecture series will familiarize students with the operation of a controlled fission chain reaction. Students will gain insight into the spatial, energy and temporal distribution of neutrons and reactor control and safety. Of particular interest is the challenge of presenting a model for the spatial neutron distribution without losing students in mathematics. The manner in which this obstacle will be addressed is discussed below. The topics addressed in the course are:

- Fundamental Particles

○ Building blocks of the nucleus

- Mass-energy equivalence

$\circ$ Binding energy and mass deficit

- Radioactive Decay and Interactions

○ Half life and decay constant

- Decay modes and radioactivity

- Neutron-nucleus interactions and excitation

- Cross Sections and Fission

- Probability of neutron-nucleus interaction; neutron flux

- Physical meaning of cross section; reaction rate; resonances

o Fission and its aftermath: fission products

- Physics of Multiplying Systems

- A chain reaction

- Energy release from fission

- Introduction to energy dependence of reaction rates

- Critical Reactors

- Neutron slowing down and thermalization

- Life cycle of a neutron in a critical reactor

- The six factor formula

- Reactivity and Control

- Multiplication factor and reactivity

- Mechanisms for passive reactor control: reactivity coefficients

- Mechanisms for active reactor control: control rods, shim 
- Time Dependence

○ Delayed neutrons and precursors, criticality versus prompt criticality

○ Point kinetics model: the Inhour equation

- Transients - startup and shutdown

- Neutron Spatial Distribution

$\circ$ Conceptual discussion of spatial distribution of neutrons in a fixed-source geometry; analogy to diffusion

- Neutron current and Fick's Law

- Neutron balance in a volume element: the diffusion equation

Homework assignments assigned on alternate days from those associated with the reactor engineering lectures and a final exam will be used to measure the student understanding of the material.

\section{$\underline{\text { Reactor Engineering }}$}

The second morning session of lectures will focus on engineering aspects of nuclear power. Their goal is to provide the students with a basic understanding of commercial nuclear reactor design. Students will gain an understanding of thermodynamics, core design, and reactor control. The particular features for this course are:

- Heat Removal

- Energy removal in a nuclear reactor

○ Power distributions

- Fuel pin heat transport with derivation of temperature profile across fuel, gap, and cladding.

- Two Phase Flow and Departure from Nucleate Boiling (DNB)

○ Two phase flow

- Nuclear limits

- DNB and burnout

- Thermodynamic Cycles

○ Carnot efficiency

- Rankine Cycle

○ Brayton Cycle

- Fuel Depletion

○ Fuel burnup

- Transmutation

○ Conversion and breeding

- Fuel management

- Economics and Design Principles

- Economics of nuclear power

- Electric utility economics

- Cost components

- Demand considerations

- Nuclear power costs

- Light Water Reactors

○ Boiling water reactor (BWR) 
- Pressurized water reactor (PWR)

- Other Commercial Reactor Designs

- Gas cooled reactor

- Canadian deuterium uranium (CANDU)

- Reaktor bolshoy moshchnosti kanalniy (RBMK)

- Liquid metal fast breeder reactor (LMFBR)

- Next Generation Reactors

- Gen III reactors

- Gen IV reactors

- Nuclear Regulation and Licensing

- Nuclear Regulatory Commission (NRC)

- Regulation of nuclear power plants

- Steps for licensing

Homework assignments assigned on alternate days from those associated with the reactor physics lectures and a final exam will be used to measure the student understanding of the material.

\section{$\underline{\text { Reactor Laboratory }}$}

This course will contain afternoon laboratory sessions. The UT-Austin Mark II TRIGA reactor will be utilized for these experiments. The laboratories will last for approximately two to three hours. Students are then expected to utilize the remainder of time in the afternoon to analyze the data collected and write laboratory reports. The laboratories will consist of the following:

- Reactor Tour with Startup

○ General reactor tour

- Startup checklist

- Approach to low-power critical

- Increase of reactor power to $\sim 1 \mathrm{MW}$

- View of Čerenkov radiation once at full power

- Half-life Measurement

- Irradiation of sample that activates to short-lived radionuclide (e.g. aluminum)

- Measurement of sample decay

- Calculation of half-life

- Neutron Activation Analysis

- Irradiation of standard reference material in pneumatic system

- Acquire spectrum with HPGe detector

- Identify nuclides

- Subcritical Multiplication

- Conduct 1/M experiment with control rod movement.

- Predict control rod position where reactor goes critical.

- Prompt Jump and Prompt Drop

$\circ$ Conduct three prompt jump experiments

- Utilize asymptotic period method to calculate reactivity

- Conduct two rod drops and calculate reactivity. 
- Xenon Buildup

- Prior to first class of the day, the students will start up the reactor and note control rod positions.

- Reactor will continue at full power operation all day and students will note rod positions.

- Students will calculate reactivity difference of critical control rod positions throughout the day.

- Fuel Temperature Coefficient of Reactivity

- Reactor power will be adjusted in increments from $1 \mathrm{~kW}$ to $950 \mathrm{~kW}$.

- Students will note control rod positions and fuel temperature at each power level.

- A calculation of reactivity vs. fuel temperature will be made.

- Power Calibration

- Reactor will be run without cooling for 30 minutes.

- The pool water temperature will be monitored throughout this time.

$\circ$ The reactor power will be calculated based on the temperature increase of a known volume of water.

- Reactor Pulse

$\circ$ Reactor pulses of approximately $\$ 1.50, \$ 2.00$, and $\$ 2.50$ will be conducted.

- Students will record maximum power, temperature, and pulse full width at half maximum for each reactivity insertion.

\section{Conclusions}

The Summer Nuclear Engineering Institute for Texas and Big 12 Undergraduates will offer its sixteen enrollees a unique and valuable educational experience, one centering on the experimental facilities available at the Nuclear Engineering Teaching laboratory and especially the TRIGA research reactor. The Institute will therefore serve its students in two critical ways: it will expand their experiential knowledge base in ways not possible at their home institutions, making them more attractive and accomplished candidates for employment or graduate studies, and it will heighten student interest in, and awareness of, careers within the nuclear industry where their talents are sorely needed.

We view this aggressive program as the kick-off for a prestigious, recurring Institute that will serve a very large body of students who do not have access to facilities comparable to those of the Nuclear Engineering Teaching Laboratory. In particular, we are excited to reach out to institutions that have historically served minority or disadvantaged populations. We anticipate that the graduates of the Institute will be both better prepared for, and more aware of, the career and graduate study opportunities within our field.

\section{Bibliography}

1. Luchman, E., "The Resurgence of Nuclear Energy," Graduating Engineer, Winter-Spring, 2007.

2. Peters, K. "Power Play," Government Executive, July 16, 2007.

3. http://www.areva.com/servlet/careers/humanresources/keydatateams-en.html, website verified January 3, 2009. 